\title{
A Mixed-Method Study of How Instructors Design for Learning in Online and Distance Education
}

\author{
Quan Nguyen ${ }^{1}$, Bart Rienties², Denise Whitelock ${ }^{3}$
}

\begin{abstract}
The use of analytical methods from learning analytics (LA) research combined with visualizations of learning activities using learning design (LD) tools and frameworks has provided important insight into how instructors design for learning. Nonetheless, there are many subtle nuances in instructors' design decisions that might not easily be captured using LA tools. Therefore, this study sets out to explore how and why instructors design for learning in an online and distance higher education setting by employing a mixed-method approach, which combined semistructured interviews of 12 instructors with network analyses of their LDs. Our findings uncovered several underlying factors that influenced how instructors designed their modules and highlighted some discrepancies between instructors' pedagogical beliefs and their actual LD as captured by the Open University Learning Design Initiative (OULDI). This study showcases the potential of combining LA with qualitative insights for a better understanding of the complex design process in online distance higher education.
\end{abstract}
Notes for Practice
- Learning analytics has provided tools and methods to understand how instructors design for learning.
- The learning design process was strongly influenced by institutional policies and management.
- Study skills, workload, and subject disciplines are important factors in designing online courses.
- Co-designing and redesigning are prominent in the learning design process of online education.
- A mixed-method approach can provide an in-depth understanding of how and why instructors design their courses for online and distance education.

\section{Keywords}

Learning design, learning analytics, mixed-method

Submitted: 14/10/19 — Accepted: 05/10/20 — Published: 17/12/20

Corresponding author ${ }^{1} E$ mail: quanngu@umich.edu Address: School of Information, University of Michigan, MI 48109, Ann Arbor, USA, ORCID ID: https://orcid.org/0000-0001-8937-5121

2Email: bart.rienties@open.ac.uk Address: Address: Institute of Educational Technology, The Open University, Milton Keynes, MK7 6AA, UK, ORCID ID: https://orcid.org/0000-0003-3749-9629

${ }^{3}$ Email: denise.whitelock@open.ac.uk, Address: Institute of Educational Technology, The Open University, Milton Keynes, MK7 6AA, UK, ORCID ID: https://orcid.org/0000-0002-9897-4975

\section{Introduction}

Teaching entails delivering information and planning and designing learning activities, resources, and technologies to help students achieve their goals (Goodyear, 2015; Persico, Pozzi, \& Goodyear, 2018). However, there is often a lack of feedback on which elements of a learning design (LD) work, for whom, and in which circumstances. Two strands of research in education have emerged that can help educators gain better insight into the teaching and learning process. LD is defined as "a descriptive framework for teaching and learning activities ('educational notation'), and to explore how this framework can assist educators to share and adopt great teaching ideas" (Dalziel, 2015, p. 4). Research in LD has developed a wide range of tools and frameworks to document and visualize sequences of learning activities designed by instructors and to guide them through the LD process (AUTCLearningDesign, 2002; Cross, Galley, Brasher, \& Weller, 2012; Hernández-Leo et al., 2018; Koper \& Manderveld, 2004; Laurillard, Kennedy, Charlton, Wild, \& Dimakopoulos, 2018). Through the transition from implicit to explicit representations of LD, instructors can reflect on their practices while reusing and adapting good instructional approaches from others.

In parallel to LD, learning analytics (LA) has emerged as a field in this decade since the first Learning Analytics Knowledge (LAK) conference in 2011. LA is defined as "the measurement, collection, analysis and reporting of data about students and 
their contexts, for purposes of understanding and optimising learning and the environments in which it occurs" (Ferguson, 2012). LA research typically collects a large amount of data about students, such as demographics, course performance, activity logs (Macfadyen \& Dawson, 2010), interactions on discussion forums (Wise, Cui, Jin, \& Vytasek, 2017), and open text from essays or course evaluations (Ullmann, 2019). By taking advantage of advanced analytical techniques such as machine learning (Ullmann, 2019), text mining, and social network analysis (Wise et al., 2017), LA has created practical applications to support the learning process.

Although LA and LD have different origins, there exists a strong synergy between the two fields, which was acknowledged at the first LAK conference (Lockyer \& Dawson, 2011) and in subsequent discussions (Bakharia et al., 2016; Griffiths, 2017; Mangaroska \& Giannakos, 2018; Mor, Ferguson, \& Wasson, 2015; Persico \& Pozzi, 2015). On the one hand, LA provides data and tools to test pedagogical assumptions in LD against actual student interactions. On the other hand, LD provides the necessary contextual overlay to better understand observed student behaviour and to translate LA findings into actionable insights (Lockyer \& Dawson, 2011). Prior empirical works have shown the benefits of embedding LD in LA, such as improving predictive accuracy of academic performance (Gašević, Dawson, Rogers, \& Gasevic, 2016); understanding the impact of LD on student engagement, satisfaction, and performance (Rienties \& Toetenel, 2016); and exploring the navigation sequence of learning activities (Ifenthaler, Gibson, \& Dobozy, 2018).

A large number of LD tools and frameworks have been developed over the years to capture and describe sequences of learning activities. Early examples are Educational Modelling Language (EML) (Koper \& Manderveld, 2004) and the Learning Activity Management System (LAMS) (Dalziel, 2003), while more recent ones include Learning Design Studio (Law, Li, Herrera, Chan, \& Pong, 2017), Learning Designer (Laurillard et al., 2018), the Integrated Learning Design Environment (ILDE) (Hernández-Leo et al., 2018), and the Open University Learning Design Initiative (OULDI) (Conole, 2012). Previous work has reported that LD tools were positively perceived by instructors in facilitating new teaching ideas (Laurillard et al., 2018; Toetenel \& Rienties, 2016a), supporting a collaborative design process among practitioners (Hernández-Leo et al., 2018), and making the LD process more systematic (Dalziel, 2003; Koper \& Manderveld, 2004). While prior research has provided important evaluations of LD tools from a user-experience perspective, only a few studies have explored how instructors design courses on a large scale in practice (Rienties, Toetenel, \& Bryan, 2015; Toetenel \& Rienties, 2016b).

For example, using OULDI, Toetenel and Rienties (2016b) analyzed 157 LD visualizations at the Open University (OU) and found that the majority of modules used assimilative activities (i.e., reading, watching, listening) and assessment activities (i.e., assignments, exams). On average, assimilative and assessment activities accounted for $39.27 \%$ and $21.50 \%$ of the total workload, respectively. Rienties et al. (2015) identified four patterns of LD among 87 modules, which they labelled constructivist, assessment-driven, balanced-variety, and social-constructivist. While these studies provide important insight into our understanding of LD, they do not explore how LD changes throughout the length of a course. For example, instructors use a wide range of learning activities varying from week to week or day to day throughout a course (Nguyen, Huptych, \& Rienties, 2018). The order and sequence of how learning activities are structured will potentially influence the effectiveness of the learning process. Therefore, the first research question of this study will address the gap in our understanding of how instructors design for learning in distance education through the use of LA:

RQ1: What does LA tell us about the LD in online and distance higher education?

Although the documentation and visualization of LD can make instructors' pedagogical decisions more explicit, many factors behind the scenes may not be visible to LD tools such as OULDI. These include pedagogical beliefs, personal experience, composition of the student body, and "politics" within institutions. Extensive research in the field has shown that LD is a multifaceted process that involves multiple stakeholders with different factors interacting in the process of designing and implementing teaching and learning activities. For instance, Bennett, Agostinho, and Lockyer (2015) conducted 30 interviews across 16 Australian universities to explore key influences that shape university instructors' design decisions. The authors identified student-related factors (e.g., cohort profile, learning objectives, feedback from past sessions), instructorrelated factors (e.g., prior experience, pedagogical beliefs, self-belief), and context-related factors (e.g., colleges, institutional requirements, resources) that influenced how instructors engaged in the design process (Bennett et al., 2015). Therefore, the second research question will explore the underlying factors that influence instructors' LD processes:

RQ2: What are the driving factors behind instructors' LD in online and distance higher education?

\section{Methods}

\subsection{Study context}

This mixed-method study took place at the OU, the largest academic institution in the UK and in Europe, with 117,935 enrolled students in 2017/18 ${ }^{1}$. As a pioneer in distance-learning models since 1969, the OU offers more than 200 qualifications and 400

${ }^{1}$ https://www.hesa.ac.uk/news/17-01-2019/sb252-higher-education-student-statistics/location 
modules via a distance-learning model, which involves the use of a virtual learning environment (VLE) in conjunction with online and/or face-to-face tutorials with designated tutors.

To answer RQ1, we applied a well-known LA technique, namely network analysis, to analyze the composition of learning activities within LDs, the frequency of the activities, and the links between them (Nguyen, Rienties, \& Toetenel, 2017). Network analysis has been widely used to infer the social interactions between students, such as in online discussion forums (Wise et al., 2017). As argued by Nguyen, Rienties, and Toetenel (2017), an LD can be viewed as a network of learning activities, resources, and tools in which instructors made deliberate choices to intertwine different components to design for an optimal learning experience. However, these network structures are implicitly embedded in the course syllabus and/or weekly lesson plans. In order to incorporate LD into LA models, we need an explicit and quantifiable representation and a standardized taxonomy of learning activities that would allow for multi-course comparison.

\subsubsection{RQ1: Linking LA with LD Representations}

At the OU, each new module goes through the OULDI mapping process, which maps out all learning activities and their estimated time to complete the activities. The learning activities are categorized based on the OULDI learning activity taxonomy originally developed by Conole (2012), which consists of seven types of learning activity: assimilative, productive, assessment, communication, finding and handling information, interactive, and experiential. OULDI has subsequently been further fine-tuned and adjusted over time based upon both practical experience and LD research (Toetenel \& Rienties, 2016a). Data were collected from the OULDI Activity Profile tool (Figure 1), which was designed to help instructors map different types of learning activities across a course or sequence of learning events (Toetenel \& Rienties, 2016a).

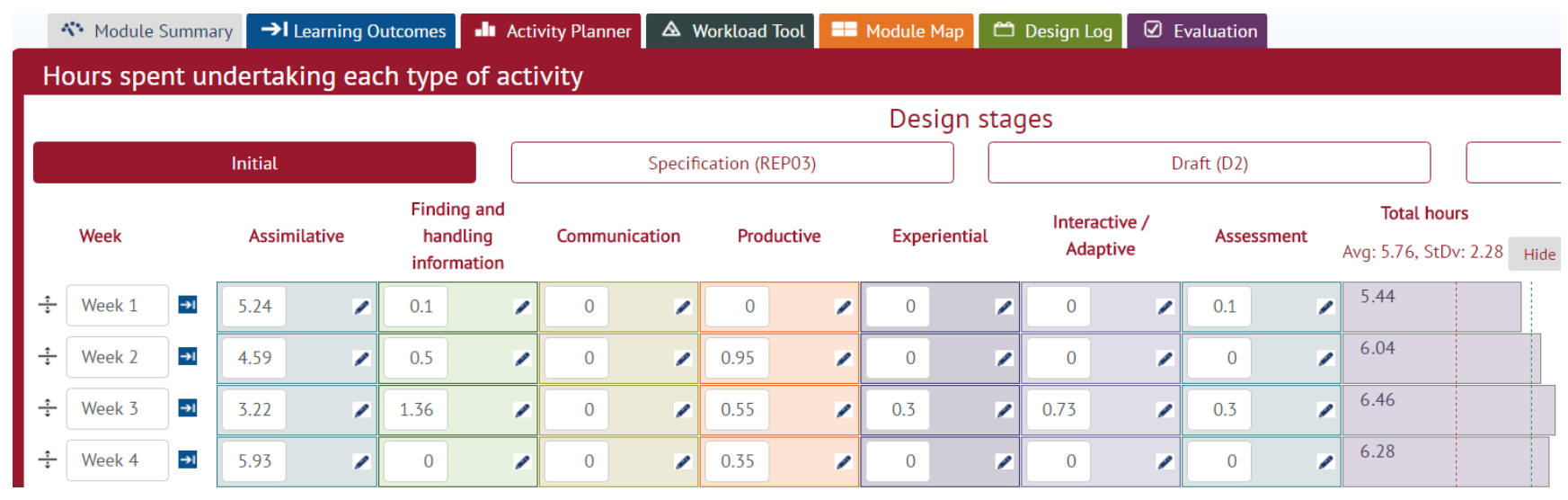

Figure 1. A screenshot from the OU Activity Profile

Assimilative activities refer to tasks that require students' attention to information. These include watching a lecture video, reading the text, listening to an audio file, and so on. Finding and handling information activities imply, for example, searching and filtering for relevant literature on a particular topic on the Internet. Communication activities refer to a range of communication practices, such as posting in a discussion forum or replying to peer comments. Productive activities represent the construction of an artefact, such as writing a summary or resolving a problem. Experiential activities provide students with opportunities to apply theories in a real-world setting, such as a case study or a field trip. Interactive/adaptive activities encourage students to apply what they have learned in an experiential environment or while interacting with a simulation. Finally, assessment activities evaluate students' understanding, such as writing an essay, taking an exam, or making a presentation (Conole, 2012). For each learning activity, an estimate is made for how long it would take an average student to complete that activity. This estimate is usually determined by the module team and is embedded in the module guide on the VLE as a guideline for students' study time allocation.

\subsubsection{Network Analysis}

Building on previous work (Nguyen, Rienties, \& Toetenel, 2017), we investigate the connections between the seven types of OULDI learning activities. The LD dataset was a weighted two-mode network, as illustrated in Figure 2. 


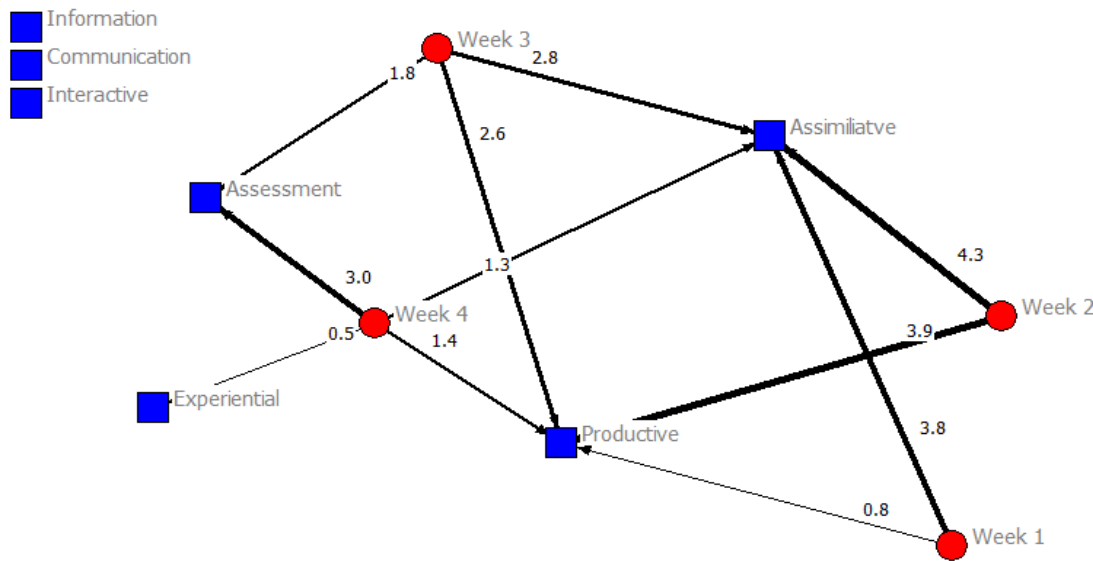

Figure 2. Two-mode network of learning activities over time

First, two learning activities (blue nodes) become connected if they were present in the same week (red nodes). For example, if instructors used assimilative activities (e.g., readings) and productive activities in week 1, then assimilative and productive activities become connected (Figure 3).

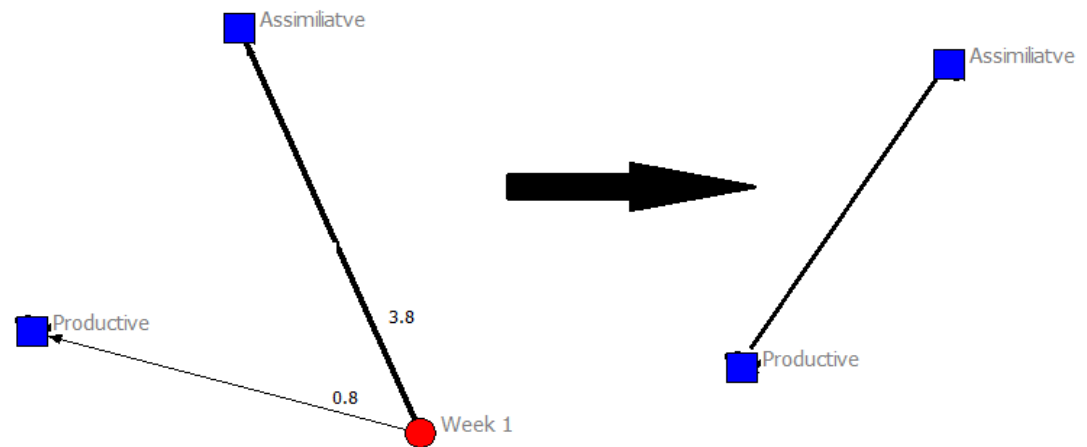

Figure 3. Transformation of a two-mode network into a one-mode network

However, simply visualizing the connection between two activity types does not tell us much about the strength of the relationship. For example, module A with 5 hours of assimilative and 1 hour of productive activities might look the same as module B with 1 hour of assimilative and 1 hour of productive. Since we captured how much time students were expected to spend on each LD each week, the weights of the two learning activities in identical weeks could also be measured. In this type of projected network, the weight of a tie from one LD to another was not necessarily equal to the weight of the reverse. For example, in Figure 3, if 3.8 hours were spent on assimilative activities and 0.8 were spent on assessment activities in the same week, then the weight from assimilative to assessment is recorded as 3.8 and the weight of the reverse is recorded as 0.8 .

Second, the weight of each tie was discounted for the number of learning activity types in the same week (Newman, 2001). It can be argued that the tie between the two activity types becomes weaker when more activity types are present in the same week. A simple analogy is the connection between two people being stronger if there are fewer people in their group. This can be generalized as follows:

$$
w_{i j}=\sum_{p} \frac{w_{i} p}{N_{p}-1},
$$

where $w_{i j}$ is the weight between $\mathrm{LD} i$ and $\mathrm{LD} j$, and $N_{p}$ is the number of learning activities in week $p$.

After transforming the dataset from a two-mode to a one-mode network, we used the Netdraw function of UCINET 6.627 (Borgatti, Everett, \& Freeman, 2002), which is based on non-metric multidimensional scaling (Kruskal, 1964), to visualize the co-occurrences between each pair of learning activities across all weeks. The nodes represent different learning activity types. The tie represents the co-occurrence of two learning activity types in the same week. The thicker the line, the larger the weights of the tie between two learning activity types.

\subsubsection{RQ2: Unpacking LD Decisions by Interviews with Instructors}

To complement the quantitative exploration of LD through network analysis, we carried out a series of semi-structured interviews with instructors to understand the underlying factors that could affect their design decisions in line with Bennett et 
al. (2015) (RQ2). Designing a module at the OU requires participation from multiple stakeholders (i.e., a production team), with several stages/checking points during the design process to ensure the consistency and quality of the module produced. Module chairs are responsible for making key design decisions, leading the production team, and overseeing the module in its production phase and in presentation (i.e., when the module is running). Therefore, module chairs were selected as the participants in this study because they are in a good position to offer valuable insight into the LD process.

In line with Creswell and Poth (2017), we continued to sample instructors until we reached a point of saturation, whereby limited new insight was added when new participants were added. There were 12 interviews in total, taking place in 10 level 1 (i.e., first-year undergraduate) modules across a wide range of disciplines. Table 1 contains descriptive information about the modules selected in this study.

Table 1. Selected Modules for Interviews (in Order of Size of Enrollments)

\begin{tabular}{llll}
\hline Module & Enrollments** & Launched since*** & Credits \\
\hline Language & 200 & 2017J & 30 \\
\hline Computing 2 & 700 & 2017J & 30 \\
\hline Arts 1 & 1400 & 2015J & 60 \\
\hline Science & 1400 & $2017 \mathrm{~J}$ & 60 \\
\hline Health* & 1700 & $2015 \mathrm{~J}$ & 60 \\
\hline Computing 1 & 2400 & $2018 \mathrm{D}$ & 30 \\
\hline Arts 2 & 2600 & $2015 \mathrm{~J}$ & 60 \\
\hline Business & 2600 & $2015 \mathrm{~J}$ & 60 \\
\hline Education* & 4000 & $2014 \mathrm{~J}$ & 60 \\
\hline Psychology & 4900 & $2015 \mathrm{~J}$ & 60 \\
\hline
\end{tabular}

* Two interviews, one for each module chair.

** Number of students at $25 \%$ fee liability date in 2018 fall semester; figures rounded to the nearest 100 for anonymization purposes.

$* * * \mathrm{~J}=$ fall semester; $\mathrm{D}=$ winter semester.

All interviews were audio-recorded using a recording device with explicit verbal permission from the participant. Interviews took place on the OU campus in a meeting room, except for two interviews taking place via Skype. The interviews lasted 45 minutes on average. The format of the interviews was semi-structured because it allowed for key topics related to the research questions to be discussed while providing flexibility for unexpected themes to emerge from the interviews at the same time (Braun \& Clarke, 2012). Since LD in the OU context is a complicated process, the flexibility of the semi-structured interview format was deemed to be more suitable for unpacking nuances in module chairs' beliefs and experience in engaging with the LD process.

\subsubsection{Thematic Analysis}

Thematic analysis was used to analyze the interview data to identify emerging themes of discussion that arose from the broad semi-structured interview questions (Braun \& Clarke, 2012). We transcribed two audio recordings in order to gain familiarity with the data, and then we used a transcription service for the rest. Next, the first author reread the interview transcripts and revisited the audio recordings to immerse himself in the data while simultaneously making notes. After that, all interview transcripts were imported into NVivo 11 to begin the systematic analysis of the data through coding. During this stage, a list of 98 codes was generated. In the third phase, initial codes were revised, modified, and merged if necessary. Emerging themes were identified by reviewing coded data for areas of similarity and overlap between codes. Themes needed to be distinctive but also to work together as a coherent and compelling narrative to answer each research question. This is an active process that combined both a deductive approach based on the LD conceptual framework by Dalziel (2015) and an inductive approach to generate themes. As a result, five themes emerged (Table 2). At this point, themes and codes were given explicit definitions in a codebook, which served as a guide map for the coding process.

Finally, the coding scheme and the emerging themes were reviewed and discussed with the second and third authors, who coded two randomly selected anonymous interviews and compared their notes. This phase is essentially about checking the consistency and quality of the codes and themes generated. Any disagreements between the two coders were discussed, and the coding scheme was revised accordingly. These narratives were then compared with the quantitative findings from RQ1 to draw connections between LD representations and instructor perspectives. The combination of checking by members and data triangulation with quantitative findings enhances the trustworthiness and credibility of the findings. All identifiable information was anonymized. 
Table 2. Summary and Definition of the Interview Codes

\begin{tabular}{ll}
\hline Code & Definition of Code \\
\hline Institutional factors & Institutional policies and management decisions influence the LD process of instructors. \\
\hline Study skills & Instructors embedded study skills in their LD. \\
\hline Student workload & Instructors considered student workload in their LD. \\
\hline Redesign/Codesign & The LD was based on existing materials/modules or how LD was a collaborative effort. \\
\hline Pedagogy & $\begin{array}{l}\text { Instructors structured learning activities such as readings, case studies, collaborations, } \\
\text { and assessment. }\end{array}$ \\
\hline
\end{tabular}

\section{Results}

\subsection{What Does LA Tell Us about LD in Online and Distance Higher Education?}

The first section of the results reported LD figures of the selected modules in this study. Four modules were missing data because they were launched in 2017/2018 and had not yet been mapped in the OULDI Activity Profile.

The six modules with available data in Figure 4 showed a common trend in which assimilative activities accounted for the majority of the total workload, followed by assessment and productive activities. However, for some modules, assimilative was the main activity (Arts 2, Psychology), while in others less than 50\% of activities were focused on assimilative. Communication activities were present in the Psychology, Business, and Arts 1 modules. There were little or no communication activities in the Health, Arts 2, and Education modules. Interactive activities were used in the Business, Arts 1, and Psychology modules. Finding and handling information activities were used with a low frequency in all six modules.

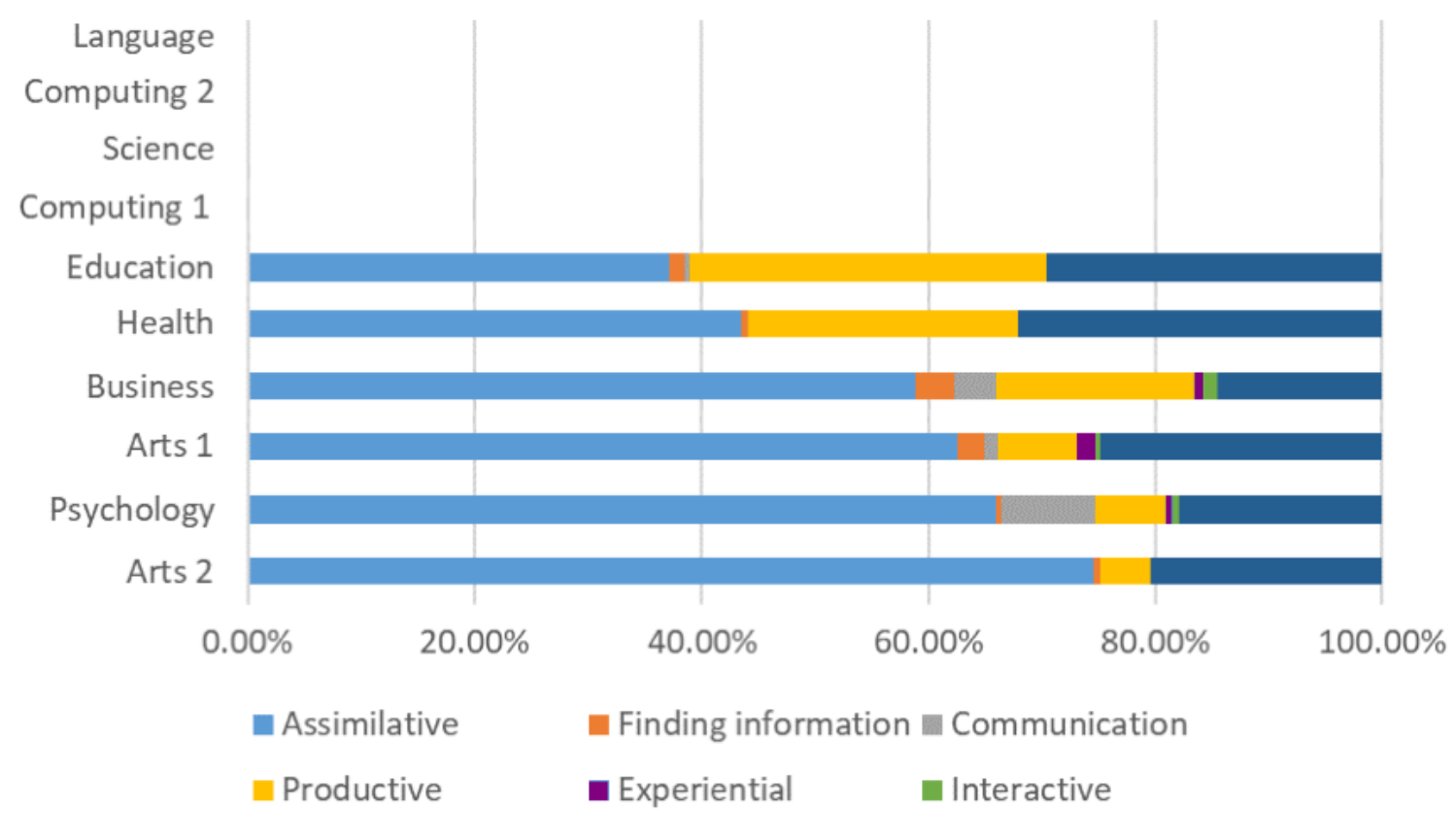

Assessment

Figure 4. LD of 10 modules in the interviews

Note: Data are missing from four new modules launched since 2017/2018.

Using our LA network approach, Figure 5 visualizes the network structure of learning activities in modules that were mapped on a weekly basis. Substantial differences in the underlying connections between these learning activities were found on a weekly basis. For example, Module 1 in Education had a strong tie between assimilative and productive activities. However, there were weak links in communication activities and in information activities. The network density of this module was $42.9 \%$, which implied a moderate variety of learning activity types. Similarly, in Module 2 in Health there was a strong link between assimilative and productive activities. However, this module did not use any interactive, experiential, or communication activities. The network density was low (28.6\%), which suggested that there was a lack of variety in the LD. The most common repertoire of practice was assimilative and productive (10 out of 31 weeks). 


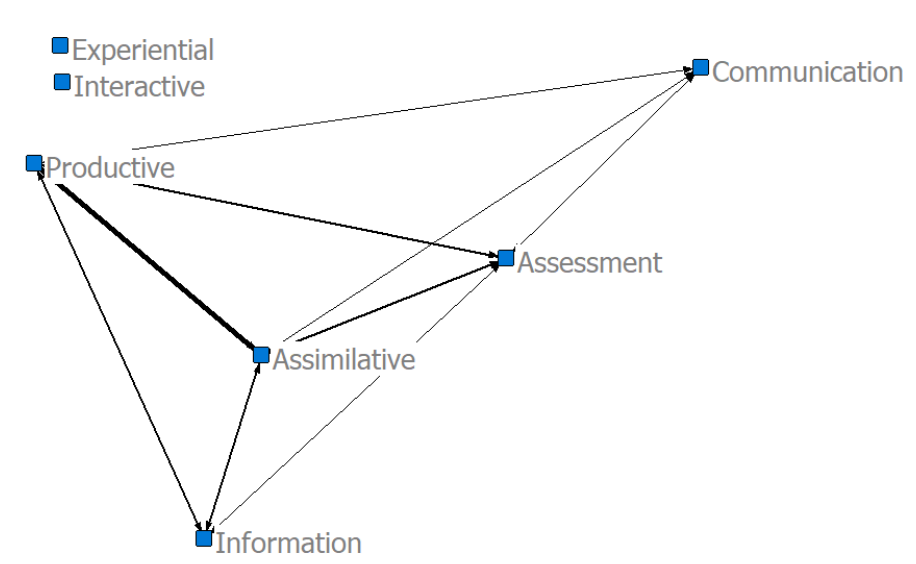

Module 1, Education $($ density $=0.429)$

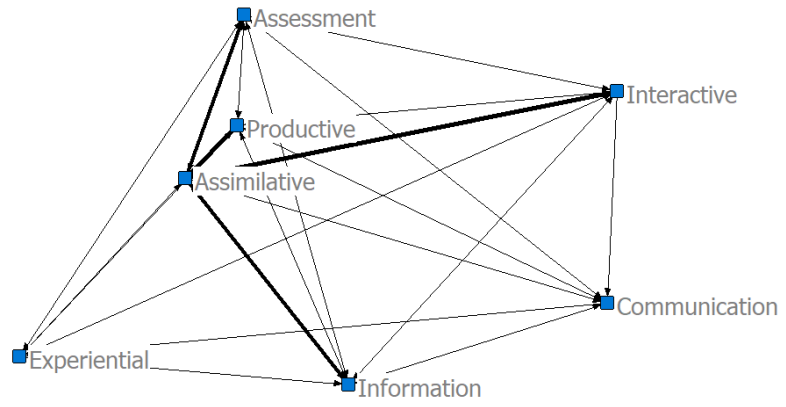

Module 4, Arts $1($ density $=0.952)$

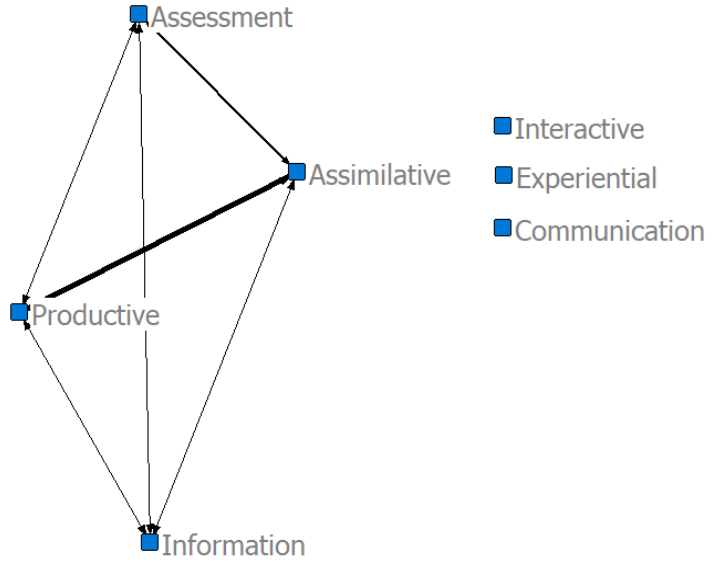

Module 2, Health $($ density $=0.286)$

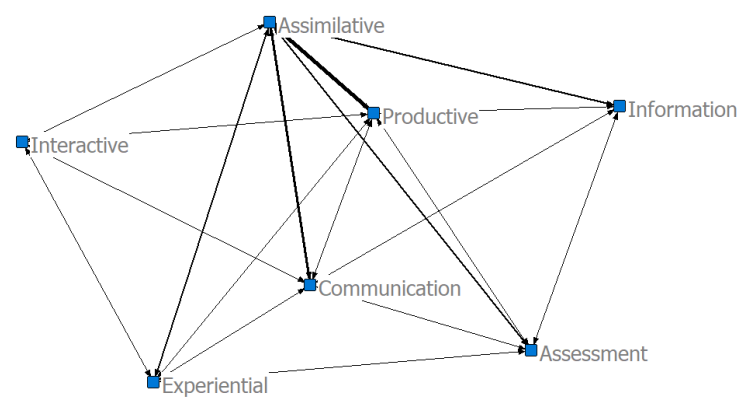

Module 5, Psychology $($ density $=0.857)$

Communication

Experiential

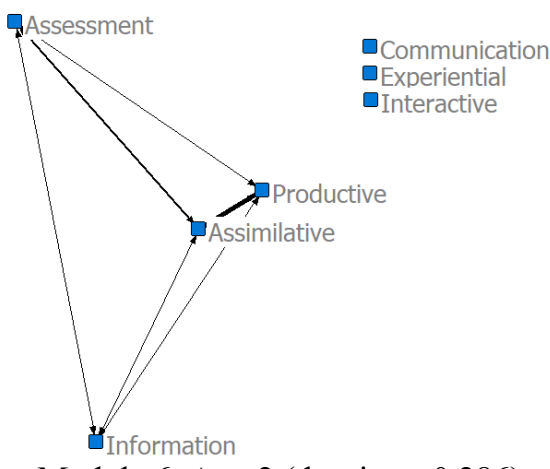

Module 6 , Arts $2($ density $=0.286)$

Figure 5. Network visualizations of five exemplary modules

Note: Module 3 in Business was not visualized because there were no data at a weekly level.

Note: The weight of ties was omitted for the sake of visual clarity.

In contrast, in Module 4 in Arts 1, there were strong connections between assimilative and assessment, assimilative and production, assimilative and interactive, and assimilative and information. There were weak links among other learning activity types. The network density was $95.2 \%$, which suggested that all seven types of learning activity were highly interconnected in the module.

Module 5 in Psychology had strong ties between assimilative and productive, assimilative and communication, assimilative and information, and assimilative and experiential. This module also had a high network density (85.7\%), which suggests that the instructor in this module employed a wide range of learning activities in their design. Module 6 in Arts 2 had a strong tie between assimilative and productive, but there were weak links or no connections with other activity types. The module had a 
low network density of $28.6 \%$, which implies that this module only used one combination of activity types in most study weeks.

In other words, our LA approach using network analysis on a weekly basis uncovered several complex LD strategies used in five different modules. The results indicated a strong influence of assimilative activities on workload and on relations with other learning activities. While assessment played an important role in all modules, instructors deliberately reduced workload on other learning activity types when they introduced respective assessment activities in a particular week. In other words, separate assessments were preferred over continuous assessments in most modules.

\subsection{What are the Driving Factors behind Instructors' Design Decisions in Online and Distance Education?}

In order to get a more detailed understanding of some of these quantitative differences in LD activities as captured by the OULDI approach, RQ2 aimed at exploring the underlying factors that influenced the respective design processes. The analysis of interview transcripts revealed five major themes.

\subsubsection{Theme 1: The LD Process Was Influenced by Institutional Factors}

A consistent theme emerging through the interviews with module chairs was the influence of management and institutional policies on the LD process. Many module chairs reported that the design process was kickstarted by decisions from management.

"When the head of the department comes and knocks on your door, you know that it's never good news. And so we was told that [MODULE CODE] needed a radical remake... When you design a module, you never ever have free rein in what you do. Often the design is strongly influenced by the senior team at the beginning stages" (Participant 1, Health).

"The learning design, to a large extent, was dictated by university initiative. It had to be turned into 60 credits from two 30 credits. It was also done very quickly, as we understand it. So not having the blank sheet to start from scratch, it has never really been outcomes" (Participant 6, Arts 1).

The influence of management and institutional policies also restricted the autonomy of module chairs when making decisions about LD. Many participants mentioned that their LD decisions regarding assessment strategies were influenced by the recent change in institutional policy, the so-called single component assessment (SCA). The concept of SCA was first introduced in 2015 to support the OU's strategic objective to improve student retention and progression. Traditionally, OU modules included both a continuous assessment component, such as tutor-marked assessments (TMAs) or computer-marked assessments (iCMAs), and an examinable component, such as exams or end-of-module assessment (EMA).

"Originally we were told that we should have a portfolio at the end. And for TMA's and a portfolio and that this was something that was even, that was passed down from LTI (Learning \& Teaching Innovation). We didn't have much say about it" (Participant 3, Education).

"It was going to be one or the other, and modules would end with either an exam or an EMA, which would be an extended essay. So, very conventional. There had been a faculty decision that every module would include iCMAs, so we knew that we would be including an iCMA" (Participant 5, Psychology).

The SCA initiated an assessment strategy based on SCA, whereby a student's module grade (including pass status) can be determined solely through a straight average of all of the assessment tasks within one component. That usually means exams or EMAs were replaced by a continuous assessment type such as TMAs. After a few years of piloting, the SCA was adopted as a default approach for all level 1 and level 2 modules in 2018.

"Over the years, we have reduced the number of assessments and now students have 4 TMAs, which in line with the recent development at the OU (i.e., single-component assessment)" (Participant 12, Language).

"Things to do with retention are big issues at the moment. Getting that information early and being able to respond to it is important. The problem is we've just had yet another institutional changed forced on us in that we've just gone to single component assessment module, starting in [October 2018]. we think students will add up how many marks they've got, and they will choose not to submit things when they've got accumulated their marks" (Participant 6, Arts 1).

To summarize, it is not unusual for a learning and teaching strategy together with an assessment policy to drive LD in a well-governed higher-education institution.

\subsubsection{Theme 2: The LD Process Involved Redesigning and Co-designing}

As part of the OU quality enhancement process, each module follows a life cycle review every four or five years. The purpose of the life cycle review is the review point for making a decision to end, amend, or extend the life of a module. Most module chairs indicated that their modules were not designed from scratch, often involving redesigning an existing module or combining existing modules. Learning materials and contents were often reused and adapted to the new module.

"The module is [MODULE CODE], kind of the third version of level 1 [subject] language and culture module, it was first produced in 1997 we was involved in the very first production of it. It was the then remade and now it's been made again but this time it wasn't just a revisioning but a full remake implementing a lot of curriculum and features" (Participant 12, Language). 
"It was called [PREVIOUS MODULE CODE], which was a 30-credit module, and we was chairing that, and then

[MODULE CODE] came up as the replacement to turn it into a 60-credit module" (Participant 8, Business).

In some modules, the production process was a joint effort between two module chairs. The process of co-designing a module can offer diverse perspectives on LD as well as distribute the responsibility and workload more equally. Participants positively acknowledged the role of co-designer (i.e., co-chair) in the LD process.

"We co-chair with [CO-CHAIR NAME] and that's been really important because having two of us working on this module closely has been really productive in terms of trying to address issues like retention, progression, and getting beyond the day-to-day issues that come up and starting to looking into the future a bit" (Participant 4, Education).

\subsubsection{Theme 3: Developing Study Skills in LD}

The OU is committed to providing equal opportunities to all students regardless of their background. Most undergraduate modules have no formal entry requirements. For this reason, the OU has an incredibly diverse population of students from different age groups with a wide variety of prior qualifications (Nguyen, Thorne, \& Rienties, 2018). Some students need more support than others because they left schools, dropped out many years ago, and/or retired. This may make returning to an academic environment a daunting experience because they may lack appropriate study skills for the university level. Therefore, it is essential for LD at level 1 to build up students' academic skills in preparation for their learning journey at the OU. Most interviewed module chairs acknowledged the diversity of student profiles and the need to scaffold an inclusive LD for all.

"What we're more worried about is the larger number of students for whom they would not have been in formal education for any length of time prior to this and may not have had sufficient preparation. They need to be able to have assessment tasks that are sufficiently demanding but they're accessible and understandable" (Participant 4, Education).

"We have students who didn't realize that engineering had any maths in it. We have those students who did and were scared of it, and still hate it. And then we have those ones who are fantastic at maths, so a bit of my role is mitigating the tensions between those three groups, because there's one group, 'This is easy. we've done this before.' Then you've got another group, 'We don't know what to do.' So, that's part of it” (Participant 10, Computing 1).

"What we'd been asked to do was to rewrite it in such a way that it better scaffolded students who came to the module with few or no previous educational qualifications and would, for the first bit, be more of an access course in order to sort of induct them into higher education and then take them through. So, by the end of it they were pretty much good level one students" (Participant 2, Health).

Most participants emphasized the need to gradually build up student study skills in parallel with subject knowledge to help them prepare for education at the university level.

"We redesigned the trajectory so that running across the entire module was a skills development strategy, in which throughout the module the students were taught how to perform a certain skill, and they had activities to perform that skill in the learning guide. So, for example, note taking, was one skill in the first block. And the other skill was paraphrasing and writing a summary. And so, students were taught to perform these skills, and then the assessment task at the end of the first block would take a piece of writing, and can you take notes from it and summarize the writing? Write it in your own words. So really, really ultra-basic, really, really simple, and what we were trying to do was build up, establish the building blocks of the components of essay writing" (Participant 1, Health).

"In terms of the keys things that we wanted to do, is so one thing that was really very much in the forefront of our minds was how do we prepare students for level 2 study and in particular this module was focusing on programming and problemsolving skills" (Participant 10, Computing 1).

Participants also underlined the importance of clarity and consistency in instructions for level 1 modules.

"And so those activities tend to follow a fairly predictable sequence, so generally speaking, we don't do a lot of mixing it up. We have a strong belief that what a student should do is, is know exactly what they're in for week by week" (Participant 1, Health).

"So, in terms of the design, it's making that accessible and very kind of straightforward. So, we make the tempo of the module very, very straightforward. We produced kind of readings. As in we wrote the readings, in terms of the material. And we're having an online spine" (Participant 8, Business).

\subsubsection{Theme 4: Workload as a Key Issue in LD}

Most module chairs raised concerns about students having too much work. The majority of OU students have a full-time or part-time job and/or caring commitments in parallel to their study. Having too many learning activities or over-complex activities at the beginning could be very off-putting to students, who might have just returned to studying after a long time.

"There's always just, there was too much material. And the usage complexity was extremely high. So, the module would bring together several sources of information, all contained in different books. So, the student would have to buy two books, and they would also have a resource book they'd have to read in addition to learning guide, and they would also have a CD, a DVD that they would have to watch" (Participant 1, Health). 
"There were too many questions. we mean the study skills, the, you know, reading for academic purposes or writing for academic purposes. We were asking maybe 20, 25 activities in one study week. Which again, because it was 10 hours, they're often very short activities, but students just found that overwhelming" (Participant 3, Education).

Keeping a balanced and consistent study workload is essential to student success at level 1 modules. Many participants mentioned that they have deliberately cut down the workload and reduced the complexity of instructions when redesigning their modules.

"So that was one thing, we reduced the learning, the usage complexity, we reduced the number of activities the students had to do. So, what they did was that, before, up till that point, [MODULE CODE] had quite a frenetic pace. So, at 22 activities per learning guide, the students were always moving around doing things and shifting gears. And we think that students didn't do the activities as a result. It was just too many for them to do" (Participant 1, Health).

"In the first two [presentations] we wanted to do that. One question per topic, but we quickly realised that was too much, and that was producing too much stuff and too much stress for both student and tutor. So, we actually changed that within first presentation" (Participant 9, Science).

Participants also proactively estimated the study workload of their learning materials and kept it consistent throughout the weeks.

"We are very much encouraged to have the same workload each week, and we think that's what we have always done and are trying to do. It's useful to get advice sometimes in the middle of writing module. In our early draft, we try to put timing against everything. A while ago we even published this to students. This would take you so long etc. We kind move away from that because we know that some students take this much time and others take this much time so there are lot of variations. We also have developmental testing, a small chunk of study materials, and the testers say how long it took them. In early draft, we will put timing against activities, and the author brief would be to make the week exactly to that length" (Participant 12, Language).

\subsubsection{Theme 5: LD Varied across Modules and Disciplines}

Module chairs indicated that a wide range of learning activities were used in their module, depending on the discipline and the content. For some modules, the learning pattern is relatively traditional. A typical week of learning activities often includes reading, listening, watching, and activities that help student reflect on the learning materials.

"So generally, a week of learning would start off with some kind of activity which is designed to sensitize a student to a topic area, to place the topic area at the student's fingertips... and then there will activities that will involve some kind of assimilative work in which we explain an idea or a theory or body of knowledge, so an expository activity. And those expository activities could be asking them to go and do a bit of reading, or to go off and look at a piece of, find some reading on something. And then the flow will lead towards so sort of application type activity in which we would ask them to watch a, look at a case study and understand, apply a theory they've just read about to that piece of, to that case study" (Participant 1, Health).

"Quite a lot of reflection, quite a lot of, common jamming some ways, you know, old school, old style, you activities of, you know, here's a [inaudible 00:09:02], here's an idea from the reader chapter, what's your response to it? Typing into a free text box. And then when they'd type that up, then comments to the module team had written would come up below that" (Participant 3, Education).

Interestingly, the excerpts from the module chairs in Health and Education aligned with the quantitative figures shown in Figure 4. Both modules used a lot of productive activities (32\% for Education and $24 \%$ for Health). To put it in perspective, the average percentage of productive activities of 37 modules in RQ1 was $17.6 \%$, with a standard deviation of $12.4 \%$. This means that the Education and Health modules reported here were 0.8 to 1.2 standard deviations higher in productive activities than the average.

In other modules, instructors made use of interactive activities, case studies, brainstorming, or quizzes. The excerpt from the module chair in the Business module also aligned with Figure 4, which showed that the Business module had the highest percentage of interactive activities (3\%), compared to the average of $2.2 \%$ in interactive activities reported in RQ1.

'It's varieties. It's quizzes, a little bit of analysing new responses to quizzes, it's case studies, it's tutor group forum discussions. We also have one case study, which we filmed in Germany, which runs through that whole module. We've got a narrative. So, we say, okay, we've got a business here that students can look at, because it's kind of theme-based.... And what we thought, it'd be nice to have this case study that we keep on returning to" (Participant 8, Business).

"We always start with something active, so we wouldn't start with giving information. It would always start with activating prior knowledge or bringing in their own experience. For example, we might ask students to have a quick brainstorm, or what they already know about the topic, or engage them in a mini interview. Then we would be very keen to make it clear to students how their learning is accumulated, so based on something they have learnt in previously" (Participant 12, Language). 
Collaborative activities remain a challenge for most participants in their LD. While collaborative activities were perceived to be useful for student learning, they were not well received by students because of concerns about their grades depending on others.

"We think there is a problem about students taking up the opportunities to be doing things together online. Students don't seem to like very much the collaborative research work that they would routinely do somewhere else, particularly if they are concerned that their grade depends upon other people in their group performing" (Participant 5, Psychology).

One participant also mentioned the resistance from tutors when they introduce collaborative activities. Interestingly, this finding also matched with Figure 4, which showed that there were no communication activities in the Health module.

"Yeah. It's missing because we took it out, and we took it out consciously. So, in the 2005/2006 version of [MODULE $\mathrm{CODE}]$ there was a collaborative activity that was regarded as disastrous by tutors, and by the module lead. And because we worked with tutors when putting together [MODULE CODE], that was one piece of advice we did listen to. And we removed it, and we never put any other genuinely piece of collaborative activity in the module... we was aware that the organization of collaborative work was always problematic because tutors never quite knew who was still registered in the module when it came to organize collaborative activity and assigning people. In the early days, $50 \%$, sometimes up to $56 \%$ of the students would drop out of the module before the end. And so, if you're trying to organize collaborative activities when half your student body has left, it was really, really difficult for the tutors" (Participant 1, Health).

Other participants acknowledged the importance of collaborative activities in LD. However, they expressed that collaboration in distance learning is challenging and there is a lot of work to be done to get it right.

"We don't quite think we got collaboration right. Collaboration between students in online environment, it's very difficult.... They [students] just require to interact with each other. Just like discuss things on forums and things like that. And it's just the nature of OU students, we mean we have a lot of students who choose to study with the OU, so they don't have to go to a university and, you know, meet and even look at other people. And so, a lot of them are very adverse to just interacting. And they actually felt that they chose this degree, so they didn't have to. And so, for a lot of them, just ordinary communication is quite stressful. So, it's difficult because it's a requirement for progression in any scientific discipline.... Well in life, to be honest. But in any scientific discipline you have to work with other people. So, it's a learning outcome we can't really remove" (Participant 9, Science).

In summary, the LD process undertaken by module teams was influenced by such factors as institutional policies, student profiles, and co-designing/redesigning activities. OU module chairs scaffolded learning activities to increase the study skills of their students in line with the designated learning outcomes for each module while making sure there was a balanced and consistent workload. A wide range of pedagogy was used across modules and disciplines. Nonetheless, most instructors reported challenges in embedding collaborative activities into the curriculum due to negative feedback from students and tutors.

\section{Discussion}

This study explored how and why instructors design for learning in an online and distance setting by employing a mixedmethod approach, which combined LA visualizations and network analyses of 10 LDs at the OU with subsequent semistructured interviews of 12 instructors to unpack how and why teachers made these respective LD decisions. In terms of RQ1, the use of network analysis LA techniques on learning artefacts highlighted several common but also unique connections between different types of learning activities in LDs. We observed common patterns, such as the predominant use of assimilative and productive activities, and yet diverse variations in assessment strategies in different courses. We illustrated how LA approaches like network analysis can help us identify some of these common design patterns across a large number of courses, which could serve an important role in curriculum management. At the same time, using this LA approach, we were able to conclude that many instructors (i.e., module chairs) seem to make several common and conscious LD decisions, such as reducing other activities in a week when assessment activities are scheduled.

While the recorded LD decisions in OULDI provide an important proxy of an LD in a respective module on a week-byweek basis, some of the underlying reasons why instructors might have designed a particular combination of learning activities may not be apparent using solely the network analysis approach. Therefore, in RQ2 we specifically explored how and why 12 instructors made these design decisions, whereby we uncovered important nuances that are hidden from the quantification of learning artefacts.

We found five main themes emerging from the triangulation of data. First, instructors emphasized the importance of building up student study skills at level 1 modules in parallel with subject knowledge. The OU offers a rich set of resources to develop study skills, such as how to write an essay, how to find information, and how to revise for exams, and computer skills ${ }^{2}$. These study skills are crucial to the development of OU students in general, but even more so for students who lack academic skills or have not been in an academic environment for a long time. For example, in a large-scale analysis of 123,916

${ }^{2}$ http://www2.open.ac.uk/students/skillsforstudy/

ISSN 1929-7750 (online). The Journal of Learning Analytics works under a Creative Commons License, Attribution - NonCommercial-NoDerivs 3.0 Unported (CC BY-NC-ND 3.0) 
undergraduate OU students in 205 modules from 2015 to 2017, Nguyen, Thorne, and Rienties (2018) showed that students with no formal qualifications or less than A-levels were $37 \%$ to $50 \%$ less likely to pass a module than students with A-levels. Clearly, the prior educational background had a strong effect on the academic performance of OU students. Therefore, it is important to equip students with the study skills to succeed in a distance education setting.

Second, student workload was another central aspect of LD at the OU (Chambers, 1992; Whitelock, Thorpe, \& Galley, 2015). Module chairs in this interview study have highlighted potential problems of having excessive study workload or overcomplex instructions for level 1 students. This finding was supported by RQ1, which showed a large variation in workload both within a module and between modules (Nguyen, Rienties, \& Toetenel, 2017). To overcome this issue, module chairs reduced the number of learning activities, removed non-essential content, and kept the instructions straightforward and consistent throughout the module.

Third, assessment design has been a core aspect of OU retention strategies, which had a wider impact on LD decisions for level 1 modules. Participants mentioned that their assessment design was driven by the changes in OU's policy that made SCA the default approach since $2018^{3}$. The premise of SCA is that students should be assessed in a consistent manner, through either continuous assessments or exams. As a result, most modules decided to remove the exam or EMA and replace it with a TMA. The switch to an SCA strategy has been well received by the module team because it seemed to improve the retention rate, which is a strong motivator for students to show what they know versus what they can only remember.

Fourth, this study also revealed two unique aspects that are the by-products of the complex module production process at the OU, namely co-designing and redesigning. The OULDI process is often different from that of a traditional university, where a professor/lecturer usually has full autonomy over the design process and the course content. Conversely, module materials at the OU have to undergo a peer-review process by multiple stakeholders before they are officially used in the LD. Because of this long and complex quality assurance process, module materials are often reused until the new module cycle review comes in every four or five years. On the one hand, this process ensures the quality and consistency of the learning materials, which is beneficial to OU students. On the other hand, the rigidity of this process raises a question as to what extent the OU module materials are up to date or can be updated without significant barriers from the quality assurance process. At the same time, because of this complex module production process, the OU module team is often made up of two or more academics. This co-design process was perceived to be useful by the participants because it offered new perspectives on LD and progression and retention issues. For some large modules with thousands of students and hundreds of tutors, having more than one module chair means that the responsibility and workload can be shared among team members. But this co-design process perhaps did not occur "naturally" but as a combined result of the complex LD process and pressure for accountability from management.

In terms of the pedagogy used in LD, a wide range of learning activities was adopted by module chairs across different modules. In line with findings from RQ1, most participants mentioned the use of assimilative activities, such as reading, listening, and watching, and productive activities, such as analyzing, reflecting, and criticizing. In some STEM modules, there were more interactive and experiential activities because the module chairs strongly believed in learning by doing/practising. Collaborative activities were perceived as important but challenging by most participants. Module chairs mentioned resistance from students taking part in collaborative activities because of the dependencies in grading and the resistance from tutors to manage group works, which can be time-consuming. This was again reflected in RQ1, which indicated that only a small proportion of LD was dedicated to communication and collaborative activities. This is in sharp contrast to findings from Rienties and Toetenel (2016), who found that the primary predictor for student retention was communication activities. In other words, what students enjoy and what is good for them might not be related.

This finding was supported by prior research in collaborative learning and online collaboration (Cherney, Fetherston, \& Johnsen, 2017; Kreijns, Kirschner, \& Jochems, 2003). Some students may be entrenched in passive learning strategies and exhibit strong levels of resistance when they are asked to collaborate with each other. There are many explanations for this, such as miscommunication (Kreijns et al., 2003), accountability problems (Cherney et al., 2017), and cultural differences (Mittelmeier, Rienties, Tempelaar, \& Whitelock, 2018). In online and distance learning settings such as the OU, the challenges for collaborative learning are even more salient because students are often complete strangers coming from different backgrounds or age groups, communicating through asynchronous channels such as a VLE (Thorpe, 2002). Simply creating a medium for communication (e.g., opening an online discussion forum for a group of students) will not guarantee an effective collaboration experience. Multiple factors, such as group cohesion, trust, sense of community, and culture, should be considered (Kreijns et al., 2003).

An obvious limitation of this study is the specific context in which it was conducted, which might limit generalization in other settings. Furthermore, as highlighted elsewhere in this special issue, there are several other conceptualizations of LD approaches that could potentially highlight a more nuanced understanding of the interaction between LD and LA. While the

${ }^{3}$ https://help.open.ac.uk/documents/policies/assessment-handbook 
OULDI approach has proved to be useful for many instructors due to its relatively simple seven categories, and has proved to be a very good and solid predictor of actual student engagement (Nguyen, Rienties, Toetenel, Ferguson, \& Whitelock, 2017), LD decisions are often multi-level in nature and strongly embedded in more complex sets of decisions about learning outcome goals, task sequences, and feedback. Therefore, we strongly encourage other researchers to explore whether using similar network analysis LA approaches in their contexts might provide comparable or contrasting insights.

\section{Conclusion}

In conclusion, this study investigated how instructors designed for learning in online and distance education by employing a mixed method of network analysis with semi-structured interviews of 12 module chairs in 10 modules. We showcased the LA application of network analysis for standardized comparisons of various LDs. In most modules, the triadic combination of assimilative, productive, and assessment activities remained the dominant repertoire of practice. Communication and experiential learning activities had only a limited presence in most LDs. Through this process, we identified common design patterns and variations between courses, which can be integrated as part of institutional curriculum management.

We also underlined the importance of going beyond the quantification of learning artefacts. Our interviews revealed a strong influence of management and institutional policy on teachers' design decisions. Building up study skills and maintaining a balance of workload were considered the main priorities of LD. Interestingly, while instructors saw the value of communication and collaborative learning activities, they were put off by resistance from both students and tutors. Hence, the final product of LD lacks communication activities.

In going forward, we encourage institutions to utilize the power of LA to make existing teaching practices more explicit, so they can be compared, analyzed, and linked to academic outcomes and learning processes. We also emphasize the need to actively gather instructors" "voices" and engage them in the development of LA for LD.

\section{Declaration of Conflicting Interest}

The authors declared no potential conflicts of interest with respect to the research, authorship, and/or publication of this article.

\section{Acknowledgments}

This work is funded by the Leverhulme Open World Learning grant at the Open University UK.

\section{References}

AUTCLearningDesign. (2002). Predict-observe-explain: Designer's voice - Context. Retrieved from http://www.learningdesigns.uow.edu.au/exemplars/info/LD44/more/03Context.html

Bakharia, A., Corrin, L., de Barba, P., Kennedy, G., Gašević, D., Mulder, R., ..., Lockyer, L. (2016). A conceptual framework linking learning design with learning analytics. Proceedings of the 6th International Conference on Learning Analytics and Knowledge (LAK '16), 25-29 April 2016, Edinburgh, UK, (pp. 329-338). New York, NY: ACM. https://dx.doi.org/10.1145/2883851.2883944

Bennett, S., Agostinho, S., \& Lockyer, L. (2015). Technology tools to support learning design: Implications derived from an investigation of university teachers' design practices. Computers \& Education, 81, 211-220.

https://dx.doi.org/10.1016/j.compedu.2014.10.016

Borgatti, S. P., Everett, M. G., \& Freeman, L. C. (2002). Ucinet for Windows: Software for social network analysis. Harvard, MA: Analytic Technologies. Retrieved from https://sites.google.com/site/ucinetsoftware/home

Braun, V., \& Clarke, V. (2012). Thematic analysis. In H. Cooper, P. M. Camic, D. L. Long, A. T. Panter, D. Rindskopf, \& K. J. Sher (Eds.), APA handbook of research methods in psychology, Vol 2: Research designs: Quantitative, qualitative, neuropsychological, and biological. (pp. 57-71). Washington, D.C.: American Psychological Association. https://dx.doi.org/10.1037/13620-000

Chambers, E. (1992). Work-load and the quality of student learning. Studies in Higher Education, 17(2), 141-153. https://dx.doi.org/10.1080/03075079212331382627

Cherney, M. R., Fetherston, M., \& Johnsen, L. J. (2017). Online course student collaboration literature: A review and critique. Small Group Research, 49(1), 98-128. https://dx.doi.org/10.1177/1046496417721627

Conole, G. (2012). Designing for learning in an open world (Vol. 4). New York, NY: Springer Science \& Business Media. https://dx.doi.org/10.1007/978-1-4419-8517-0

Creswell, J. W., \& Poth, C. N. (2017). Qualitative inquiry and research design: Choosing among five approaches. London, UK: Sage Publications. https://us.sagepub.com/en-us/nam/qualitative-inquiry-and-research-design/book246896 
Cross, S., Galley, R., Brasher, A., \& Weller, M. (2012). Final project report of the OULDI-JISC Project: Challenge and change in curriculum design process, communities, visualisation and practice. York, UK: JISC. Retrieved from http://www.jisc.ac.uk/media/documents/programmes/curriculumdesign/OULDI_Final_Report instit\%20story.pdf

Dalziel, J. (2003). Implementing learning design: The learning activity management system (LAMS). In G. Crisp, D. Thiele, I. Scholten, S. Barker, \& J. Baron (Eds)., Proceedings of the 20th Annual Conference of the Australasian Society for Computers in Learning in Tertiary Education (ASCILITE), 7-10 December 2003, Adelaide, Australia (pp. 593-596). Wollongong, N.S.W.: Australasian Society for Computers in Learning in Tertiary Education.

Dalziel, J. (2015). Learning design: Conceptualizing a framework for teaching and learning online. New York, NY: Routledge.

Ferguson, R. (2012). Learning analytics: Drivers, developments and challenges. International Journal of Technology Enhanced Learning, 4(5-6), 304-317. https://dx.doi.org/10.1504/IJTEL.2012.051816

Gašević, D., Dawson, S., Rogers, T., \& Gasevic, D. (2016). Learning analytics should not promote one size fits all: The effects of instructional conditions in predicting academic success. The Internet and Higher Education, 28, 68-84. https://dx.doi.org/10.1016/j.iheduc.2015.10.002

Goodyear, P. (2015). Teaching as design. HERDSA Review of Higher Education, 2, $27-50$.

Griffiths, D. (2017). The use of models in learning design and learning analytics. Interaction Design and Architecture(s) Journal-IxD\&A, 33, 113-133. Retrieved from http://www.mifav.uniroma2.it/inevent/events/idea2010/doc/33 6.pdf

Hernández-Leo, D., Asensio-Pérez, J. I., Derntl, M., Pozzi, F., Chacón, J., Prieto, L. P., \& Persico, D. (2018). An integrated environment for learning design. Frontiers in ICT, 5(9). https://dx.doi.org/10.3389/fict.2018.00009

Ifenthaler, D., Gibson, D., \& Dobozy, E. (2018). Informing learning design through analytics: Applying network graph analysis. Australasian Journal of Educational Technology, 34(2). https://dx.doi.org/10.14742/ajet.3767

Koper, R., \& Manderveld, J. (2004). Educational modelling language: Modelling reusable, interoperable, rich and personalised units of learning. British Journal of Educational Technology, 35(5), 537-551. https://dx.doi.org/10.1111/j.0007-1013.2004.00412.x

Kreijns, K., Kirschner, P. A., \& Jochems, W. (2003). Identifying the pitfalls for social interaction in computer-supported collaborative learning environments: A review of the research. Computers in Human Behavior, 19(3), 335-353. https://dx.doi.org/10.1016/S0747-5632(02)00057-2

Kruskal, J. B. (1964). Multidimensional scaling by optimizing goodness of fit to a nonmetric hypothesis. Psychometrika, 29(1), 1-27. https://dx.doi.org/10.1007/BF02289565

Laurillard, D., Kennedy, E., Charlton, P., Wild, J., \& Dimakopoulos, D. (2018). Using technology to develop teachers as designers of TEL: Evaluating the learning designer. British Journal of Educational Technology, 49(6), 1044-1058. https://dx.doi.org/10.1111/bjet.12697

Law, N., Li, L., Herrera, L. F., Chan, A., \& Pong, T.-C. (2017). A pattern language based learning design studio for an analytics informed inter-professional design community. Interaction Design and Architecture(s), 33, 92-112. Retrieved from http://www.mifav.uniroma2.it/inevent/events/idea2010/doc/33_5.pdf

Lockyer, L., \& Dawson, S. (2011). Learning designs and learning analytics. Proceedings of the 1st International Conference on Learning Analytics and Knowledge (LAK '11), 27 February-1 March 2011, Banff, AB, Canada (pp. 153-156). New York, NY: ACM. https://dx.doi.org/10.1145/2090116.2090140

Macfadyen, L. P., \& Dawson, S. (2010). Mining LMS data to develop an "early warning system" for educators: A proof of concept. Computers \& Education, 54(2), 588-599. https://dx.doi.org/10.1016/j.compedu.2009.09.008

Mangaroska, K., \& Giannakos, M. N. (2018). Learning analytics for learning design: A systematic literature review of analytics-driven design to enhance learning. IEEE Transactions on Learning Technologies, 12(4), 516-534. https://dx.doi.org/10.1109/TLT.2018.2868673

Mittelmeier, J., Rienties, B., Tempelaar, D., \& Whitelock, D. (2018). Overcoming cross-cultural group work tensions: Mixed student perspectives on the role of social relationships. Higher Education, 75(1), 149-166. https://dx.doi.org/10.1007/s10734-017-0131-3

Mor, Y., Ferguson, R., \& Wasson, B. (2015). Editorial: Learning design, teacher inquiry into student learning and learning analytics: A call for action. British Journal of Educational Technology, 46(2), 221-229. https://dx.doi.org/10.1111/bjet.12273

Newman, M. E. (2001). Scientific collaboration networks. II. Shortest paths, weighted networks, and centrality. Physical Review E, 64(1), 016132. https://dx.doi.org/10.1103/physreve.64.016132

Nguyen, Q., Huptych, M., \& Rienties, B. (2018). Linking students' timing of engagement to learning design and academic performance. Proceedings of the 8th International Conference on Learning Analytics \& Knowledge (LAK '18), 5-9 March 2018, Sydney, Australia (pp. 141-150). New York, NY: ACM. https://dx.doi.org/10.1145/3170358.3170398 
Nguyen, Q., Rienties, B., \& Toetenel, L. (2017). Unravelling the dynamics of instructional practice: A longitudinal study on learning design and VLE activities. Proceedings of the Seventh International Learning Analytics \& Knowledge Conference (LAK '17), 13-17 March 2017, Vancouver, BC, Canada (pp. 168-177). New York, NY: ACM. https://dx.doi.org/10.1145/3027385.3027409

Nguyen, Q., Rienties, B., Toetenel, L., Ferguson, R., \& Whitelock, D. (2017). Examining the designs of computer-based assessment and its impact on student engagement, satisfaction, and pass rates. Computers in Human Behavior, 76, 703-714. https://dx.doi.org/10.1016/j.chb.2017.03.028

Nguyen, Q., Thorne, S., \& Rienties, B. (2018). How do students engage with computer-based assessments: Impact of study breaks on intertemporal engagement and pass rates. Behaviormetrika, 45(2), 597-614. https://dx.doi.org/10.1007/s41237-018-0060-1

Persico, D., \& Pozzi, F. (2015). Informing learning design with learning analytics to improve teacher inquiry. British Journal of Educational Technology, 46(2), 230-248. https://dx.doi.org/10.1111/bjet.12207

Persico, D., Pozzi, F., \& Goodyear, P. (2018). Teachers as designers of TEL interventions. British Journal of Educational Technology, 49(6), 975-980. https://dx.doi.org/10.1111/bjet.12706

Rienties, B., \& Toetenel, L. (2016). The impact of learning design on student behaviour, satisfaction and performance: A cross-institutional comparison across 151 modules. Computers in Human Behavior, 60, 333-341. https://dx.doi.org/10.1016/j.chb.2016.02.074

Rienties, B., Toetenel, L., \& Bryan, A. (2015). Scaling up learning design: Impact of learning design activities on LMS behavior and performance. Proceedings of the Fifth International Conference on Learning Analytics and Knowledge (LAK '15), 16-20 March 2015, Poughkeepsie, NY, USA (pp. 315-319). New York, NY: ACM. https://dx.doi.org/10.1145/2723576.2723600

Thorpe, M. (2002). Rethinking learner support: The challenge of collaborative online learning. Open Learning: The Journal of Open, Distance and e-Learning, 17(2), 105-119. https://dx.doi.org/10.1080/02680510220146887a

Toetenel, L., \& Rienties, B. (2016a). Analysing 157 learning designs using learning analytic approaches as a means to evaluate the impact of pedagogical decision making. British Journal of Educational Technology, 47(5), 981-992. https://dx.doi.org/10.1111/bjet.12423

Toetenel, L., \& Rienties, B. (2016b). Learning design - Creative design to visualise learning activities. Open Learning: The Journal of Open, Distance and e-Learning, 31(3), 233-244. https://dx.doi.org/10.1080/02680513.2016.1213626

Ullmann, T. D. (2019). Automated analysis of reflection in writing: Validating machine learning approaches. International Journal of Artificial Intelligence in Education, 29(2), 217-257. https://dx.doi.org/10.1007/s40593-019-00174-2

Whitelock, D., Thorpe, M., \& Galley, R. (2015). Student workload: A case study of its significance, evaluation and management at the Open University. Distance Education, 36(2), 161-176. https://dx.doi.org/10.1080/01587919.2015.1055059

Wise, A. F., Cui, Y., Jin, W., \& Vytasek, J. (2017). Mining for gold: Identifying content-related MOOC discussion threads across domains through linguistic modeling. The Internet and Higher Education, 32, 11-28.

https://dx.doi.org/10.1016/j.iheduc.2016.08.001 